\title{
Geophagy As A Risk Factor For Helminth Infections In Pregnant Women In Lusaka, Zambia
}

\author{
Shinondo $^{1}$ Cecilia J., and Grace Mwikuma ${ }^{2}$.
}

\begin{abstract}
It has been reported that geophagy is closely associated with helminthic diseases ${ }^{(1,2,3)}$ and it has been especially linked to Ascaris and Trichuris infections among pregnant women ${ }^{(4)}$. Hitherto proof of existence of viable infective ova in geophageal material has been anecdotal.
\end{abstract}

This study was undertaken to determine the possible direct role of geophagy in helminthiases of pregnant women. Eighty-five pregnant women between the ages of 15 and 44 years of age were recruited into the study in order to determined the prevalence of geophagy among pregnant women resident in high a density and low income areas of Lusaka. The study showed that 31,8\% of the pregnant women interviewed practised geophagy at the time of the study, and that $71 \%$ had a history of deliberate ingestion of soil. The preferences for the soil types were ranked as clay, termite mounds from tree trunks, and soft stone. Some respondents reported a preference for smoked, roasted or baked clay soils. Perceived benefits of geophagy included diminished craving when they ate soil $(35.2 \%)$, prevention of vomiting and nausea ( $32.4 \%$ ), and others ingested soil for the taste $(32.4 \%)$. Most women who were interviewed $(91.8 \%)$ were aware of possible health risks involved in geophagy such as constipation, heartburn, anemia, coughing, infections with worms, and abdominal discomfort.

This study sought to recover and identify helminth ova from a total $3.15 \mathrm{Kg}$. Submitted or collected soil types ingested by the women in the study. No ova was recovered from the soil samples by both the sedimentation and Zinc Sulphate, as well as saturated sodium chloride floatation techniques. These techniques reliably yielded Ascaris, Schistosome, and hookworm ova and Strongyloides larvae in spiked control specimens. Notably, Ascaris lumbricoides, and Trichuris

\footnotetext{
${ }^{1}$ Department of Biomedical Science,

School of Medicine, University of Zambia,

P.O. Box 50110, Lusaka, Zambia.

${ }^{2}$ Chest Diseases Laboratory,

Ministry of Health, Chelstone,

Lusaka, Zambia
}

trichiura ova require moisture to survive and embryonate. The soils ingested by the respondents were dried, some of which are roasted, backed or smoked before ingestion and thus rendering them unsuitable for the survival of ova, let alone the support of embryonated ova which are the infectious stages.

This study has demonstrated that no ova were recovered from any of the soil types preferred by the pregnant women, and as such geophagy was an unlikely risk factor for geohelminth infections. Other explanations for the high helminth infection rates among pregnant women recorded in the literature must be sought, such as pica, poor hygiene, and unsanitary environments.

\section{INTRODUCTION}

Geophagy or geophagia is exclusively applicable to the eating of soil, 2,5,6 and is distinct from "pica" which is defined as the eating of non -food substance such as rock powder, chalk, dirt, and other materials by humans. Pregnant women, patients with chronic kidney disease and young children ${ }^{7,8}$ practice soil pica and ingest unusually high amounts of soil to the order of $1,000-$ $5,000 \mathrm{mg}$ per day 9 .

Other groups that practice pica are the children aged six and younger and individuals who are developmentally delayed ${ }^{10}$. Geophagy is recognised as the intentional ingestion of clay soils excavated from known and usually uncontaminated sources, rather than the consumption of surface soils from residential properties. Geophagy is associated with cultural practices and has been recorded from traditional human societies on all continents, and is commonest among pregnant women ${ }^{11}$.

In Zambia and Zimbabwe, the main sources of geophageal soils which $90 \%$ of the rural women ingest are giant termite mounds ${ }^{11}$. Reasons for geophagy vary for example, in Malawi it is reported that it is surprising for a pregnant woman not to practice geophagy since it is believed that it is how a woman knows that she is pregnant. Also the taste of clay is claimed to diminish nausea, discomfort and vomiting in "morning 
sickness" ${ }^{11}$. Unlike the practice of pica, geophagous people are very specific and particular about the type of soil they eat. Geophagy can to be a risk factor for geohelminths, because the eating of contaminated soil is among the major modes of transmission for helminth parasites. Geohelminths: Trichuris trichiura, Taenia, Ascaris, and toxocara species are the parasites which are most likely to be found in the soil mainly eaten by geophagists ${ }^{11}$.

There is no direct evidence that geophagy is a risk factor for helminthiasis. This study sought to demonstrate the presence of viable helminth ova in geophagical soils ingested by pregnant women.

\section{LITERATURE REVIEW}

A study conducted by Gilardi and others ${ }^{12}$ on the Peruvian rainforest Parrot, revealed that geophagy has three possible functions. The first is that it provides grit with which the birds grind food in their gizzards. The second is that it provides essential minerals and this has been suggested for wild ungulates, livestock, rabbits, and butterflies and pregnant women. Soils sold in Ghanaian markets to pregnant women are richer in iron and copper than the dietary supplement pills made by pharmaceutical companies especially in prenatal use ${ }^{11}$. The third function of geophagy proposed for ungulate livestock is to buffer the lumen contents ${ }^{11,12}$.

In humans, geophagy has been said to be useful as: famine food, ${ }^{4}$; food detoxifier to counteract toxins and poisons, ${ }^{11}$; filler for nutritional deficiency, ${ }^{13}$; and medicinal purposes, for example, Kaopectate, which is used to treat diarrhoea and acid-stomach upset ${ }^{11}$. On the other hand, geophagy has public health implications ${ }^{14}$ as it can expose the consumers to elements that are hazardous to human health like cadmium and arsenic.

Well-preserved helminth ova have been recovered in soil samples from archaeological excavations ${ }^{15,16,17,18}$. These discoveries however, did not indicate whether or not viability tests were performed on ova from these archaeological soil samples. Twelve ${ }^{12}$ coprolites and 66 soil samples from 41 pits, dating from $11^{\text {th }}$ to $16^{\text {th }}$ centuries A.D. were examined and a wide spectrum of parasite eggs were recovered; especially from soil samples. Identified ova included Trichuris, Ascaris, Metastrongylus, Heterakis, Ascarida, Fasciola hepatica and Toxocara ${ }^{15}$. Parasite ova recovered from other archeological samples included the four genera;
Trichuris, Ascaris, Taenia and Dicrocoelium ${ }^{17,18,19}$. During excavation of a medieval pit in Manchester eggs of Trichuris trichiura, Ascaris lumbricoides, and Dicrocoelum dendriticum were recovered. The eggs were reported to be well preserved ${ }^{16}$ but their viability was not stated.

A study in school children in Western Kenya showed that geophagy does not directly contribute substantially to the infections with soil-transmitted helminths at least in the dry season ${ }^{2}$. A cohort study conducted in Western Kenya on the role of geophagy and other risk factors for helminthiasis in pregnant and lactating women showed that geophagy significantly increased the risk of infection with Ascaris after antihelminth treatment ${ }^{1,20}$. However, none of these studies demonstrated the presence of viable helminth ova in soil types eaten by the pregnant women. The purpose of this study is to re examine the old traditional belief that geophagy is a risk factor for helminthiasis by looking for the presence of viable ova in soils consumed by geophagous pregnant women.

\section{MATERIALS AND METHODOLOGY}

The study was conducted in a high-density area of the sprawling shanty of Chawama compound in Lusaka, Zambia. The study design was a cross-sectional analytical study, and included pregnant women from the age of 15 to 44 years. An administered questionnaire was used to collect data on geophagous practices.

\section{SAMPLE COLLECTION}

The subjects identified the source, or provided the types of soils they ingested. Soil samples were also identified by the pregnant women at the market place, and purchased for the study.

\section{PROCEDURE FOR THE DETECTION OF HELMINTH OVA IN SOIL}

Soils in 3mg samples were dissolved in water and the mixture sieved through a gauze lined tea strainer. This was repeated several times to remove large particles of debris. Then Zinc sulphate and saturated sodium chloride floatation, as well as the sedimentation techniques for ova isolation were applied. Isolated ova was to be identified, counted and embryonated to test for viability. Spiked and non spiked samples were used as controls for the ova isolation techniques. 


\section{RESULTS}

\section{Geophagy Among Pregnant Women}

Eighty five pregnant women between the ages of 15 and 44 years were enrolled into the study and interviewed. Of the eighty-five pregnant women interviewed, $71 \%$ had a history of ingesting soil, but only twenty-seven $(31.8 \%)$ ingested soil, while fifty-eight $(68.2 \%)$ did not ingest soil at the time of the interview. The interviews also revealed that geophagy is often practiced even among people who are not pregnant. Among the 27 geophagic pregnant women, twelve (35.2\%) stated that they ingested soil because of cravings. Eleven (32.4\%) ate soil for its taste and the remaining eleven (32.4\%) ingested soil to prevent morning sickness.

\section{Soil Types Consumed by Pregnant Women}

Seventy-nine $(70.5 \%)$ of the subjects preferred clay to other types of soils, twenty-two (19.6\%) cited dry termite mound from tree trunks in combination with other types, nine $(8.04 \%)$ mentioned hut brick, and two $(1.8 \%)$ cited stone as the types of soil they preferred to eat (figure 1). The vendors of geophagous soils explained that clay soil was mined in specific areas in the country or imported from the Republic of Congo. Some respondents reported a preference for either smoked, roasted, or baked clay soils

Figure 1: Soil types ingested by pregnant women; pregnant women identified their preferred soil types that they consumed.

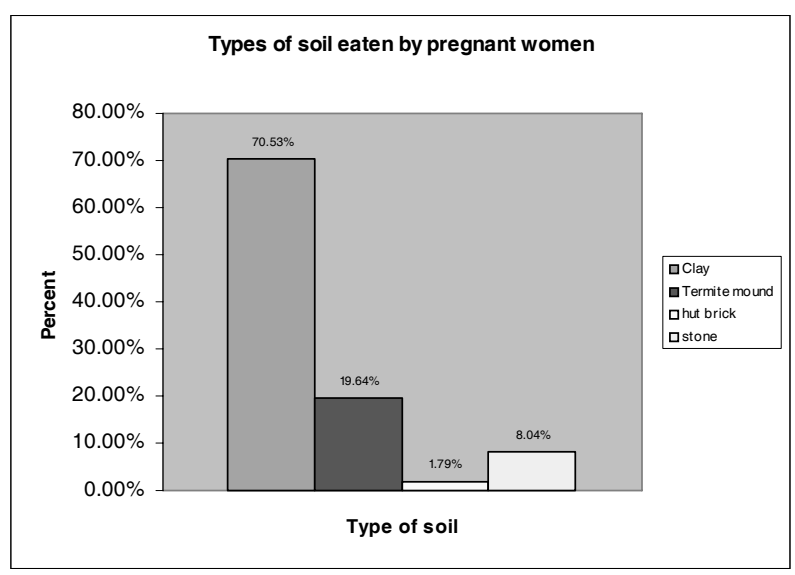

\section{Perceived Knowledge of Risks and Benefits of Geophagy}

The findings shoed that seventy-eight pregnant women $(91.8 \%)$ believed that there were risks involved in geophagy. However, seven (8.2\%) did not know that there were risks involved in geophagy . Thirty-eight (48.70\%) of the pregnant women interviewed associated geophagy with problems such as constipation, appendicitis, and abdominal discomfort. Thirty-five $(44.9 \%)$ believed worms and bacteria could possibly be transmitted through this habit. Four believed geophagy could cause heartburn and coughing. One perceived anemia to be a risk involved in geophagy (Figure2). Twenty-five (25) respondents considered geophagy a good habit and sixty (60) pregnant women did not. Eighteen (72\%) of those who said that geophagy was a good habit stated that they got satisfaction from eating, and $12 \%$ believed that the soils were a source of iron and calcium.

Figure 2: Perceived risks involved in geophagy; Respondents were asked to state the risks they believed were involved in the practice of consuming soil.

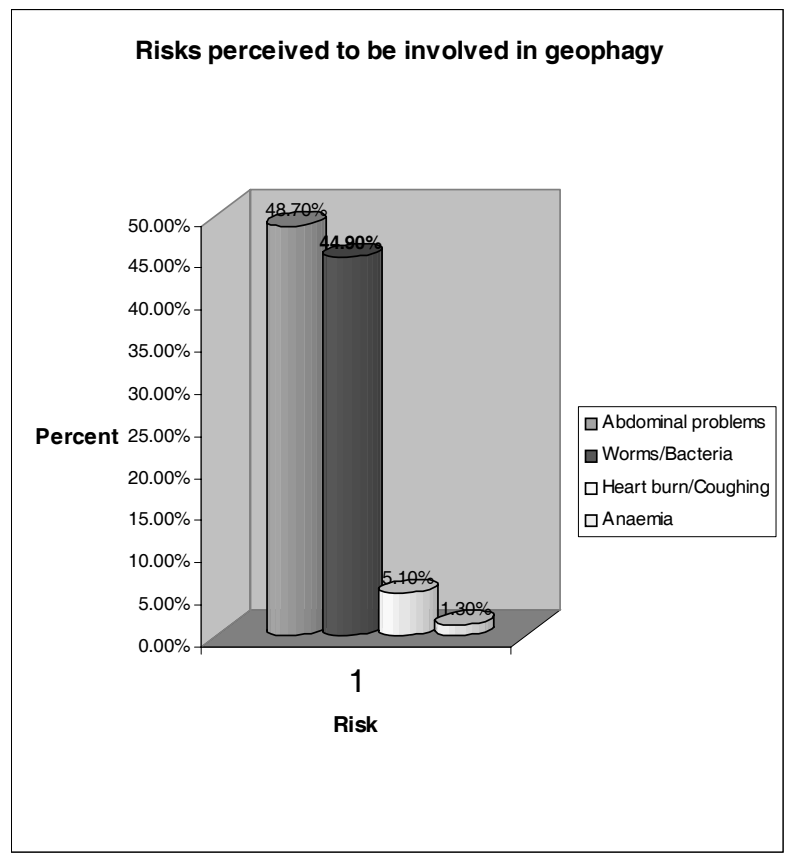

\section{Isolation of Geohelminthic Ova from Soil Types Ingested by The Pregnant Women}

The two main types of soils ingested by the pregnant women of this community were clay and termite mound. The soils were examined macroscopically and appeared desiccated and hard, and some clay soils had been roasted 
or smoked to enhance the flavor. Clay soils were either yellowish or grayish. Ova isolation was performed on a total of $3.15 \mathrm{~kg}$ of clay and termite mound. Three helminth ova isolation techniques were employed in the study; zinc sulphate flotation, super-saturated sodium chloride flotation, and the sedimentation techniques. No ova were recovered in any of the soil specimens (Table 1), but all the nine positive control specimens yielded the expected results. No ova were seen in the negative control specimen. No viability tests could be carried out since no ova were recovered

TABLE 1: Recovery ova from soil samples ingested by pregnant women

\begin{tabular}{|c|c|c|c|c|c|}
\hline \multirow[b]{2}{*}{$\begin{array}{l}\text { SPECIMEN } \\
\text { TYPE }\end{array}$} & \multicolumn{4}{|c|}{ TECHNIQUE AND NUMBER OF SAMPLES } & \multirow[b]{2}{*}{ Result } \\
\hline & Formal Ether & ZnSo4 & \begin{tabular}{|l} 
Saturated \\
Sodium \\
chloride
\end{tabular} & $\begin{array}{l}\text { Total } \\
\text { samples }\end{array}$ & \\
\hline Grayish clay & 20 & 3 & 10 & 33 & No ova \\
\hline Yellowish clay & 15 & 2 & 10 & 27 & No ova \\
\hline $\begin{array}{l}\text { Termite } \\
\text { Mound }\end{array}$ & 20 & 6 & 20 & 46 & No ova \\
\hline $\begin{array}{l}\text { Positive } \\
\text { control }\end{array}$ & 3 & 3 & 3 & 9 & $\begin{array}{l}\text { Ascaris } \\
\text { Hookworm } \\
\text { ova }\end{array}$ \\
\hline $\begin{array}{l}\text { Negative } \\
\text { Control }\end{array}$ & 3 & 3 & 3 & 9 & No ova \\
\hline
\end{tabular}

\section{DISCUSSION}

Eighty-five pregnant women were recruited into the study and a questionnaire was

administered to the women whose ages ranged from 15 to 44 years. The prevalence of geophagy was $31.8 \%$. Of those who ingested soil, $29.7 \%$ started eating soil long before they became pregnant indicating that geophagy is practiced even among people who are not pregnant

The most commonly preferred soil according to this study was the greyish and yellowish clay type which was eaten by $70.5 \%$ of the respondents. The clay is usually eaten in dry form by sucking on it, and is sometimes smoked, toasted, or baked before consumption in order to enhance the flavour. Most women (91.8\%) who were interviewed perceived possible health risks of geophagy such as constipation, appendicitis, and abdominal discomfort, worm and bacteria infections.
Parasitological results showed that the types of soil ingested by geophagous pregnant women did not contain helminth ova. It is also important to note that geohelminth ova of Ascaris lumbricoides and Trichuris trichiura require moisture to survive and embryonate. The soils ingested by the respondents were dried, and some of which were toasted, baked or smoked before ingestion, and therefore rendering them unsuitable for the survival of ova, or the support of embryonated ova which are the infective stages.

Unlike the practice of pica, geophagous people are very specific and particular about the type of soil they eat. It was discovered that the geophagical soils are commercially mined or excavated from known (and usually uncontaminated) sources at depth, rather than from the surface. The fact that some geophagous people roast the soil before they eat it, ought to render it innocuous and therefore it could not pose the risk for helminthiasis. Those who eat termite mound obtain it from the upper branches and tree trunks where it is completely dry and is not likely to be freshly contaminated. In an effort to recover ova, the soils were tested many times and examined using three different techniques.

Parasitological findings of this study proved that geophagy does not put pregnant women at risk for geohelminthic infections because no ova was isolated from the soils ingested by these women, and as such geophageal soils were an unlikely source of infection. Nevertheless geophagy could pose the risk of some other medical conditions such constipation or could contain toxic substances like mercury, or arsenic. Other explanations for the high helminthes infection rates among pregnant women recorded in the literature, such as pica, poor hygiene, and unsanitary environment must be sought. The prevention of high worm infections reported in pregnant women, must be accompanied by the promotion of good and healthy eating habits.

\section{CONCLUSION}

This study demonstrated that geophagy was not a risk factor for geohelminth infections because no ova were recovered from any of the soil samples ingested by the pregnant women. 


\section{REFERENCES}

1. Wong, M.S., Bundy, D.A.P. and Golden, M.H.N. Quantitative assessment of geophagous behaviour as a potential source of exposure to geohelminth infection. Transactions Royal Soc. Trop. Med. Hygiene (1988); 82:621-625.

2. Geissler, P.W., Mwaniki, D.L., Thiong'o, F., and Friis, H. Geophagy among school children in western Kenya. Trop. Med. Internat. Health (1997); 2(7): 624:630.

3. Akagun, O.B. Some Social aspects of helminthiasis among the people of Guman Districts, Bauchi State, Nigeria. Journal of the Topical Medicine and Hygiene (1989); 92, pp193-196.

4. Hunter, J.M. "Geophagy in Africa and the United States: A Culture-Nutrition H y p o th e s i s." Geographic review (1973); April: 170-195.

5. Al-Kanhal, M.A., and Bani I.A. Food habits during pregnancy among Saudi women. Internat. J.vit. Nutr. Res. (1995); 65; 206-210

6. Calabresse, E.J., and Gilbert, C.E. Adult soil ingestion: Estimates in Petroleum contaminated soils. School of Public Health. Environmental Health Sciences Programme (eds kostecke P7 and Calabresse Lewis E.J.) (1990); Pp. 349-356.Lewis: Amherst, USA.

7. Davies S. Qualitative estimates of soil ingestion in normal children between the ages of 2-7 years: Population based estimates using aluminium silica and titanium as soil tracer elements. Archives of Environmental Health (1990); 45: 112-122.

8. Calabresse, E.J. How much do young children ingest: An Epidemiological study. Regulation Toxicology and Pharmacology (1989); 10, 113-123.

9. Calabresse, E.J., and Stanek, E.J. Soil-pica: Not a Rare Event. Journal of Environmental Science and Health (1993); A28 (2): 373-384. 1993.

10. Calabrese, E.J., and Stanek, E.J. Soil Ingestion Estimation in Children and Adults: A Dominant Influence in Site-Specific Risk Assessment. Environmental Law Reporter (November 1998); 28 ELR 10660-10671.
11. Diamond, J. "Eat dirt". Discover (1998); Pp 70-75.

12. Gilardi, J.D., S.S. Duffey, O.A. Munn, and L.A. Tell. Biochemical Functions of geophagy in parrots: detoxification of dietary toxins and cytoprotective effects. Journal of Chemical Ecology (1999); 25:897-922.

13. Vermeer Donald., E. and Frate, Dennis, A. Geophagia. in rural Mississippi environmental and cultural contexts and nutritional implications. The American Journal of Clinical Nutrition (October 1979), 32: 2129-2135.

14. Calabrese, E.J., Stanek, E.J, James, R.C, and Stephen, M. Roberts. Soil Ingestion: A Concern for Acute Toxicity in Children. Environmental Health Perspectives (December 1997); 105(12): 13541358.

15. Bouchet, F. Recovery of helminth eggs from Archaeological Excavations of the Grand Louvre (Paris France). The Journal of Parasitology (1997); 81:785-787.

16. Taylor, E.L. Parasitic Helminths in Medieval remains. The Veterinary Records (1955);

67:216-218.

17. Bouchet, F.C., Lefevre, D. West, and Corbett. First Paleoparasitology Analysis of the midden in the Alentian islands (Alaska): Results and Limitations. Journal of Parasitology (1999); 85 (2): 369-372.

18. Horne, P and J.A. Tuck. Archeoparasitology at a $17^{\text {th }}$ Century colonial site in Newfoundland. The Journal Parasitology (1996); 82 (3): 512-515.

19. Jones, A.G., A.R. Hutchinson, and C Nicholson. The worms of Roman horses and other find the intestinal parasite eggs from unpromising deposits. Antiquity (1988); 62:275-276.

20. Ziegler, J.L. Editorial: Geophagy: A Vestige of Paleonutrition. Trop. Med. Internat. Health (1997); 2 (7): 609-611 